\title{
Genotyping of Coxiella burnetii from domestic ruminants in northern Spain
}

\author{
lanire Astobiza ${ }^{1 \dagger}$, Jeroen JHC Tilburg ${ }^{2+}$, Alvaro Piñero ${ }^{1}$, Ana Hurtado ${ }^{1}$, Ana L García-Pérez ${ }^{1 *}$, \\ Marrigje H Nabuurs-Franssen ${ }^{2}$ and Corné HW Klaassen ${ }^{2}$
}

\begin{abstract}
Background: Information on the genotypic diversity of Coxiella burnetii isolates from infected domestic ruminants in Spain is limited. The aim of this study was to identify the C. burnetii genotypes infecting livestock in Northern Spain and compare them to other European genotypes. A commercial real-time PCR targeting the IS1111a insertion element was used to detect the presence of C. burnetii DNA in domestic ruminants from Spain. Genotypes were determined by a 6-loci Multiple Locus Variable number tandem repeat analysis (MLVA) panel and Multispacer Sequence Typing (MST).

Results: A total of 45 samples from 4 goat herds (placentas, $N=4$ ), 12 dairy cattle herds (vaginal mucus, individual milk, bulk tank milk, aerosols, $\mathrm{N}=20$ ) and 5 sheep flocks (placenta, vaginal swabs, faeces, air samples, dust, $N=21$ ) were included in the study. Samples from goats and sheep were obtained from herds which had suffered abortions suspected to be caused by C. burnetii, whereas cattle samples were obtained from animals with reproductive problems compatible with C. burnetii infection, or consisted of bulk tank milk (BTM) samples from a Q fever surveillance programme. C. burnetii genotypes identified in ruminants from Spain were compared to those detected in other countries. Three MLVA genotypes were found in 4 goat farms, 7 MLVA genotypes were identified in 12 cattle herds and 4 MLVA genotypes were identified in 5 sheep flocks. Clustering of the MLVA genotypes using the minimum spanning tree method showed a high degree of genetic similarity between most MLVA genotypes. Overall 11 different MLVA genotypes were obtained corresponding to 4 different MST genotypes: MST genotype 13, identified in goat, sheep and cattle from Spain; MST genotype 18, only identified in goats; and, MST genotypes 8 and 20, identified in small ruminants and cattle, respectively. All these genotypes had been previously identified in animal and human clinical samples from several European countries, but some of the MLVA genotypes are described here for the first time.
\end{abstract}

Conclusions: Genotyping revealed a substantial genetic diversity among domestic ruminants from Northern Spain.

Keywords: Q fever, Ruminants, Genotyping, MLVA, MST, Spain

\section{Background}

Coxiella burnetii is ubiquitous and the causative agent of Q fever, a zoonotic disease [1]. Domestic ruminants are often asymptomatic carriers of $C$. burnetii and are considered the most important reservoir and source for human $\mathrm{Q}$ fever infection [2]. However, other animal species like birds, reptiles, arthropods or pets can also be infected and possibly transmit the disease to humans [1].

\footnotetext{
* Correspondence: agarcia@neiker.net

${ }^{\dagger}$ Equal contributors

'NEIKER-Instituto Vasco de Investigación y Desarrollo Agrario, Department of Animal Health, Derio, Bizkaia, Spain

Full list of author information is available at the end of the article
}

C. burnetii can cause abortions and stillbirths in goats and sheep, and infertility and endometritis in cattle [3]. Infected animals shed bacteria mainly through milk, faeces, vaginal mucus and birth products [4]. Inhalation of C. burnetii contaminated aerosols is the main route of infection for humans. C. burnetii can be transported by the wind several kilometres far from the original infected source; direct contact with animals or C. burnetii infected birth products is not always necessary [5].

Considering the impact of C. burnetii on human and animal health, the study of potential sources of infection and the characterization of strains present in an area is of great epidemiological importance. Genotypic characterization of

\section{() Biomed Central}


Coxiella burnetii is a prerequisite for surveillance purposes and for epidemiological investigation of $\mathrm{Q}$ fever outbreaks. This information is necessary to evaluate the epidemiological link between the source of the outbreak and human cases, with the final objective of establishing control measures in potential animal hosts involved in the life cycle.

Several techniques have been used to genotype and characterize $C$. burnetii strains. Techniques such as pulsed field gel electrophoresis were able to classify $C$. burnetii isolates in different groups [6]. DNA restriction fingerprints and separation by SDS-PAGE differentiated six genomic groups [7]. The analysis of the sequences of certain genes such as com 1 , icd or muc $\mathrm{Z}$ has been used for differentiating C. burnetii isolates [8-10]. More recently, multiple locus variable number tandem repeats analysis (MLVA) [11-15] and multispacer sequence typing (MST) $[16,17]$ proved to be reliable techniques, reproducible, and with a high discriminatory power. In addition, these techniques do not require previous cultivation of the bacteria which is very difficult and requires biosafety level 3 conditions, and can be implemented directly on clinical and/or environmental samples.

Q fever is an endemic disease in ruminants in several regions of Spain. Recent seroprevalence studies carried out in Northern, Central and Southern Spain revealed the importance of domestic ruminants as reservoir for this zoonosis [18-20], with herd seroprevalence ranging between $30 \%$ and $75 \%$ depending on the ruminant species, and individual seroprevalence ranging between $6 \%$ and $60 \%$. However, information on the genotypic diversity of C. burnetii isolates from domestic ruminants in Spain is limited [21]. The aim of this study was to identify the C. burnetii MLVA and MST genotypes that infect livestock in Spain and to compare them to other European genotypes.

\section{Methods}

\section{Samples}

A total of 45 samples from 4 goat herds $(\mathrm{N}=4), 12$ dairy cattle herds $(\mathrm{N}=20)$ and 5 sheep flocks $(\mathrm{N}=21)$ were included in the study. Details on the geographic origin of the samples, year of collection, type of reproductive disorders at the time of sampling, and number and type of samples collected in each farm are shown in Table 1. Ovine and caprine samples were collected for laboratory diagnosis by clinical veterinarians as part of the usual clinical practice on farms with abortions or reproductive problems, and Spanish ethical guidelines (RD 1201/ 2005) and animal welfare regulations were strictly respected. All herd owners had given an informed

Table 1 Description of material examined for C. burnetii genotyping

\begin{tabular}{|c|c|c|c|c|}
\hline Farm $^{1}$ & Location $^{2}$ & Year & Reproductive disorders & Sample type \\
\hline Gt1 & $\mathrm{AL}$ & 2010 & Abortion & 1 Placenta \\
\hline Gt2 & $\mathrm{Bl}$ & 2010 & Abortion & 1 Placenta \\
\hline Gt3 & TO & 2010 & Abortion & 1 Placenta \\
\hline Gt4 & ZA & 2005 & Abortion & 1 Placenta \\
\hline DC1 & $\mathrm{Gl}$ & 2011 & Infertility, abortion & 3 vaginal mucus, 2 milk, 1 aerosol \\
\hline DC2 & $\mathrm{Bl}$ & 2010 & Infertility & 1 BTM, 2 milk \\
\hline DC3 & $\mathrm{Bl}$ & 2010 & Infertility & 2 individual milk \\
\hline DC4 & $\mathrm{Bl}$ & 2011 & Abortion, infertility & 1 vaginal mucus \\
\hline DC5 & NA & 2011 & Infertility & 1 individual milk \\
\hline DC6 & CA & 2011 & Metritis, infertility & 1 BTM \\
\hline DC7 & LU & 2011 & Abortion, infertility & 1 individual milk \\
\hline DC8 & $\mathrm{Bl}$ & 2009 & No & 1 BTM \\
\hline DC9 & $\mathrm{Bl}$ & 2009 & No & 1 BTM \\
\hline DC10 & $\mathrm{Bl}$ & 2010 & No & 1 BTM \\
\hline DC11 & $\mathrm{Bl}$ & 2009 & No & 1 BTM \\
\hline DC12 & $\mathrm{Bl}$ & 2009 & Metritis & 1 BTM \\
\hline Sh1 & $\mathrm{AL}$ & 2004 & Abortion & 1 Placenta \\
\hline Sh2 & SS & 2007-09 & Abortion & 1 vaginal mucus, 1 individual milk, 2 faeces, 2 aerosols \\
\hline Sh3 & SS & 2008-11 & Abortion & 3 vaginal mucus, 1 placenta, 1 aerosol \\
\hline Sh4 & SS & 2008-11 & Abortion & 2 vaginal mucus, 1 aerosol, 2 dust samples \\
\hline Sh5 & SS & 2008-11 & Abortion & 1 vaginal mucus, 1 faeces, 1 aerosol, 1 dust sample \\
\hline
\end{tabular}

\footnotetext{
${ }^{1}$ Farm designation according to animal species hosted: Gt1-4 = Goat farms; DC1-12 = Dairy cattle farms; Sh1-5 = Sheep farms
}

${ }^{2}$ AL, Alava; BI, Bizkaia; TO, Toledo; ZA, Zamora; Gl, Girona; NA, Navarra; CA, Cantabria; LU, Lugo; SS, Gipuzkoa. 
consent prior to the study. Samples from cattle farms were collected within a research project on Q fever in dairy cattle farms and experimental work was officially approved by competent local authorities (Diputación Foral de Bizkaia, reference 10559, 3rd November 2010). Environmental samples consisted on aerosol samples and dust taken from animal premises. Air was sampled using a Sartorius air sampler (Air Sampler, MD8 airscan, Goettingen, Germany) at a flow rate of 100 1/min for $10 \mathrm{~min}$. and particles were collected in gelatine filters which were processed for DNA extraction.

\section{DNA extraction and PCR}

All the samples were subjected to DNA extraction using the BioSprint 96 DNA Blood Kit (Qiagen, Hilden, Germany) following the procedure as described before $[22,23]$. To rule out contamination, negative controls were included during the DNA extraction process every ten (milk, vaginals swab or environmental) samples or after each placenta sample. Extraction controls and PCR negative (water) controls were subjected to PCR amplification along with the field samples. Conventional PCR [24] was used to detect the presence of $C$. burnetii DNA. After PCR confirmation, samples were analyzed by quantitative real time PCR (qPCR) in order to quantify the bacterial burden using the commercial Kit LSI Taq-Vet Coxiella burnetii (Laboratoire Service International, Lissieu, France) according to the manufacturer's instructions. This is a duplex qPCR assay that targets the IS1111 insertion element of C. burnetii and includes a probe targeting the housekeeping gene GAPDH used as internal amplification control (IAC) to reveal possible inhibitors. PCR was performed using an ABI 7500 FAST thermocycler (Applied Biosystems, Foster City, CA, USA).

\section{Multiple locus variable number tandem-repeat analysis (MLVA)}

Two multicolor multiplex PCR assays were applied targeting six microsatellite markers containing either six or seven base pairs (bp) repeat units: 3 hexanucleotide repeat markers (Ms27, Ms28 and Ms34) and 3 heptanucleotide repeat markers (Ms23, Ms24 and Ms33).

Primer sequences were used as described before $[13,25]$. PCR was performed in a total volume of $20 \mu \mathrm{l}$ containing $1 \mathrm{U}$ of FastStart Taq DNA polymerase (Roche diagnostics, Almere, The Netherlands), $0.2 \mathrm{mM}$ dNTP's, $4 \mathrm{mM} \mathrm{MgCl}_{2}$ in $1 \mathrm{x}$ reaction buffer, $0.1-1.0 \mu \mathrm{M}$ of amplification primers and $5 \mu \mathrm{l}$ of DNA sample. Amplification products were analyzed on a MegaBACE 500 automated DNA analysis platform (GE Healthcare, Diegem, Belgium). Electropherograms were analyzed using Fragment Profiler 1.2 (GE Healthcare, Diegem, Belgium). DNA from the Nine Mile strain (RSA 493) was used as a reference. The number of repeats in each marker was determined by extrapolation using the sizes of the obtained fragments relative to those obtained using DNA from the Nine Mile strain. According to the in silico analysis, the genotype of the Nine Mile strain is 9-27-4-6-4-5 for markers Ms23Ms24-Ms27-Ms28-Ms33-Ms34, respectively. To study the genetic similarity between the MLVA genotypes obtained in the different ruminant species the minimum spanning tree method was used.

\section{Multispacer sequence typing (MST)}

A subset of 15 samples was selected for MST analyses according to animal species, sample source and origin. Methods and all sequences of primers have been previously detailed [16], and 8 out of the 10 spacers that exhibited higher variation (Cox2, Cox5, Cox18, Cox22, Cox37, Cox51, Cox56 and Cox61) were selected for genotyping. Each $20 \mu \mathrm{l}$ amplification reaction contained $0.5 \mu \mathrm{M}$ of amplification primers, $1 \mathrm{U}$ of FastStart Taq DNA polymerase (Roche diagnostics, Almere, The Netherlands), $0.2 \mathrm{mM}$ dNTP's, $1.5 \mathrm{mM} \mathrm{MgCl} \mathrm{M}_{2}$ in $1 \mathrm{x}$ reaction buffer and $5 \mu \mathrm{l}$ of DNA sample. After amplification, PCR products were cleaned and sequencing was performed using the forward and reverse primers. Sequence products were analyzed on a MegaBACE 500 automated DNA analysis platform (GE Healthcare, Diegem, Belgium) and using BioNumerics software (Applied Math, Sint-MartensLatem, Belgium). The genotypes identified by MST were compared to genotypes included in the MST database containing C. burnetii genotypes from countries throughout Europe and from several non-European countries (http://ifr48.timone.univ-mrs.fr/MST_Coxiella/mst/).

\section{Results}

All 45 samples were qPCR positive with cycle threshold (Ct) values below 35 and all of them were genotyped by MLVA. Eleven MLVA genotypes were identified in 35 (77.8\%) of the goat, sheep and cattle specimens; partial MLVA genotypes were obtained in 6 samples (13.3\%), and in 4 samples $(8.9 \%)$ no MLVA profile was obtained (Table 2). In 2 of the samples (low DNA load; high Ctvalue) that yielded a partial genotype (from farms DC4 and Sh2), the combination of identified alleles did not match with any of the full MLVA genotypes found, suggesting that they corresponded to different types. Three different MLVA genotypes were found in 4 goat farms; 7 MLVA genotypes were identified in 12 cattle herds; and 4 MLVA genotypes were identified in 5 sheep flocks (Table 2). Genotype $\mathrm{S}$ was the most abundant and present in all three ruminant species (goats, sheep and cattle), being particularly widespread in sheep (present in 3 of the 4 ovine farms sampled). Genotype $\mathrm{T}$ was found in goats and sheep. Multiple genotypes were identified in different samples obtained from the same farm, 
Table 2 MLVA genotyping results of $C$. burnetii strains isolated from domestic ruminants in Spain

\begin{tabular}{|c|c|c|c|c|c|c|c|c|c|c|c|}
\hline \multirow[b]{2}{*}{ Farm $^{1}$} & \multirow[b]{2}{*}{ Source } & \multirow[b]{2}{*}{ Origin } & \multirow[b]{2}{*}{ Year } & \multirow[b]{2}{*}{$\mathrm{Ct}$} & \multirow[b]{2}{*}{ MLVA } & \multicolumn{6}{|c|}{ MLVA-6 } \\
\hline & & & & & & Ms23 & Ms24 & Ms27 & Ms28 & Ms33 & Ms34 \\
\hline Gt1 & placenta & Alava & 2010 & 8.9 & $S$ & 1 & 11 & 2 & 3 & 2 & 3 \\
\hline Gt2 & placenta & Bizkaia & 2010 & 5.4 & $\mathrm{AE}$ & 4 & 9 & 3 & 3 & 3 & 4 \\
\hline Gt3 & placenta & Toledo & 2010 & 10.1 & $\mathrm{~T}$ & 3 & 9 & 4 & 5 & 2 & 2 \\
\hline Gt4 & placenta & Zamora & 2005 & 11.2 & S & 1 & 11 & 2 & 3 & 2 & 3 \\
\hline DC1 & Vaginal swab & Girona & 2011 & 18.3 & 1 & 6 & 13 & 2 & 7 & 4 & 9 \\
\hline DC1 & Vaginal swab & Girona & 2011 & 25.5 & 1 & 6 & 13 & 2 & 7 & 4 & 9 \\
\hline DC1 & Vaginal swab & Girona & 2011 & 14.8 & 1 & 6 & 13 & 2 & 7 & 4 & 9 \\
\hline DC1 & Individual milk & Girona & 2011 & 23.9 & 1 & 6 & 13 & 2 & 7 & 4 & 9 \\
\hline DC1 & Individual milk & Girona & 2011 & 22.3 & 1 & 6 & 13 & 2 & 7 & 4 & 9 \\
\hline DC1 & Aerosol & Girona & 2011 & 30.4 & - & $0^{3}$ & 0 & 0 & 0 & 0 & 0 \\
\hline DC2 & Individual milk & Bizkaia & 2010 & 24.2 & J & 6 & 13 & 2 & 7 & 4 & 10 \\
\hline DC2 & Individual milk & Bizkaia & 2010 & 31.7 & Mixed $^{4}$ & 6 & $?^{5}$ & 2 & $?$ & 2 & $?$ \\
\hline DC2 & BTM $^{2}$ & Bizkaia & 2010 & 26.9 & J & 6 & 13 & 2 & 7 & 4 & 10 \\
\hline DC3 & Individual milk & Bizkaia & 2010 & 28.0 & J & 6 & 13 & 2 & 7 & 4 & 10 \\
\hline DC3 & Individual milk & Bizkaia & 2010 & 23.4 & J & 6 & 13 & 2 & 7 & 4 & 10 \\
\hline DC4 & Vaginal swab & Bizkaia & 2011 & 34.2 & Partial & 0 & 13 & 0 & 0 & 0 & 3 \\
\hline DC5 & Individual milk & Navarra & 2011 & 27.7 & 1 & 6 & 13 & 2 & 7 & 4 & 9 \\
\hline DC6 & BTM & Cantabria & 2011 & 25.9 & $A C$ & 6 & 15 & 2 & 7 & 4 & 12 \\
\hline DC7 & Individual milk & Lugo & 2011 & 31.7 & $A D$ & 6 & 11 & 2 & 3 & 4 & 3 \\
\hline DC8 & BTM & Bizkaia & 2009 & 25.2 & S & 1 & 11 & 2 & 3 & 2 & 3 \\
\hline DC9 & BTM & Bizkaia & 2009 & 26.1 & $A B$ & 6 & 13 & 2 & 7 & 4 & 12 \\
\hline DC10 & BTM & Bizkaia & 2010 & 23.7 & - & 0 & 0 & 0 & 0 & 0 & 0 \\
\hline DC11 & BTM & Bizkaia & 2009 & 27.3 & । & 6 & 13 & 2 & 7 & 4 & 9 \\
\hline DC12 & BTM & Bizkaia & 2009 & 28.6 & M & 6 & 13 & 2 & 7 & 4 & 11 \\
\hline Sh1 & placenta & Alava & 2004 & 6.4 & $\mathrm{~T}$ & 3 & 9 & 4 & 5 & 2 & 2 \\
\hline Sh2 & Vaginal swab & Gipuzkoa & 2007 & 10.8 & $\mathrm{AA}$ & 3 & 9 & 5 & 5 & 2 & 2 \\
\hline Sh2 & Faeces & Gipuzkoa & 2007 & 16.0 & $\mathrm{AA}$ & 3 & 9 & 5 & 5 & 2 & 2 \\
\hline Sh2 & Faeces & Gipuzkoa & 2007 & 27.0 & AA & 3 & 9 & 5 & 5 & 2 & 2 \\
\hline Sh2 & Individual milk & Gipuzkoa & 2007 & 28.8 & $\mathrm{AA}$ & 3 & 9 & 5 & 5 & 2 & 2 \\
\hline Sh2 & Aerosol & Gipuzkoa & 2008 & 31.6 & Z & 1 & 11 & 2 & 3 & 2 & 2 \\
\hline Sh2 & Aerosol & Gipuzkoa & 2009 & 30.0 & Partial & 9 & 0 & 5 & 3 & 0 & 4 \\
\hline Sh3 & Vaginal swab & Gipuzkoa & 2008 & 6.3 & S & 1 & 11 & 2 & 3 & 2 & 3 \\
\hline Sh3 & Vaginal swab & Gipuzkoa & 2008 & 10.8 & $S$ & 1 & 11 & 2 & 3 & 2 & 3 \\
\hline Sh3 & Vaginal swab & Gipuzkoa & 2009 & 27.9 & S & 1 & 11 & 2 & 3 & 2 & 3 \\
\hline Sh3 & Placenta & Gipuzkoa & 2010 & 30.0 & S & 1 & 11 & 2 & 3 & 2 & 3 \\
\hline Sh3 & Aerosol & Gipuzkoa & 2011 & 32.8 & $S$ & 1 & 11 & 2 & 3 & 2 & 3 \\
\hline Sh4 & Vaginal swab & Gipuzkoa & 2008 & 12.6 & S & 1 & 11 & 2 & 3 & 2 & 3 \\
\hline Sh4 & Vaginal swab & Gipuzkoa & 2008 & 25.0 & Partial & 4 & 11 & 0 & 3 & 0 & 0 \\
\hline Sh4 & Aerosol & Gipuzkoa & 2008 & 28.2 & S & 1 & 11 & 2 & 3 & 2 & 3 \\
\hline Sh4 & Enviromental samples & Gipuzkoa & 2011 & 32.6 & S & 1 & 11 & 2 & 3 & 2 & 3 \\
\hline Sh4 & Enviromental samples & Gipuzkoa & 2011 & 30.9 & - & 0 & 0 & 0 & 0 & 0 & 0 \\
\hline Sh5 & Vaginal swab & Gipuzkoa & 2008 & 7.1 & - & 0 & 0 & 0 & 0 & 0 & 0 \\
\hline
\end{tabular}


Table 2 MLVA genotyping results of C. burnetii strains isolated from domestic ruminants in Spain (Continued)

\begin{tabular}{lllllllllll}
\hline Sh5 & Faeces & Gipuzkoa & 2008 & 28.5 & S & 1 & 11 & 2 & 3 & 2 \\
Sh5 & Aerosol & Gipuzkoa & 2010 & 32.9 & Partial & 0 & 11 & 0 & 0 & 0 \\
Sh5 & Enviromental samples & Gipuzkoa & 2011 & 29.7 & Partial & 0 & 0 & 0 & 3 & 0 \\
\hline
\end{tabular}

${ }^{1}$ Farm designation according to animal species hosted: Gt1-4 = Goat farms; DC1-12 = Dairy cattle farms; Sh1-5 = Sheep farms.

${ }^{2}$ BTM = Bulk tank milk.

${ }^{3} 0=$ no results obtained.

${ }^{4}$ Mixed $=2$ or more genotypes.

${ }^{5}$ ? = Multiple alleles were found per locus.

e.g. in farm Sh2, genotype AA was identified in samples taken from aborted ewes, and two different genotypes ( $\mathrm{Z}$ and a partial genotype) were identified in air samples sampled during the next two reproductive seasons (Table 2).

Figure 1 shows the relationships between all identified genotypes from goats, sheep and cattle in Spain. Clustering of the MLVA genotypes using the minimum spanning tree method showed a high diversity between the strains. Totally, three different clusters were defined. The genotypes in cluster one (I, J, M, AB and AC) were all obtained from cattle and are interconnected by repeated number changes in one of the six markers. In addition, one cattle isolate (genotype AD) differed in three markers with the cattle strains of cluster one, and also differed in at least two markers with the genotypes in cluster two (S and Z). MLVA genotype AA of cluster three, detected in sheep, differed in only one allele from genotype $\mathrm{T}$ found in a goat and a sheep sample.

MST analysis of the 15 samples selected (4 goats, 4 sheep, 7 cattle) revealed 4 different MST genotypes 8 , 13, 18 and 20 (Table 3). MST13 was identified in all three ruminant species (goats, sheep and cattle); MST20 was detected more than once, but always in cattle; MST18 was only identified once in a goat placenta; and, MST8 was identified in goat. In addition, some partial MST genotypes found in sheep (samples from farms Sh1 and Sh2) might also correspond to MST8. Correspondence between genotyping results by MLVA and MST are shown in Table 3. MLVA genotypes belonging to the same MLVA cluster all yielded the same MST genotype.

\section{Discussion}

Molecular methods are used to characterize strains and to determine relationships between isolates causing disease. In the case of Q fever, MLVA and MST techniques have been incorporated for genotyping of $C$. burnetii strains since both techniques can be performed directly on clinical and environmental samples without previous cultivation of bacteria $[11,16]$. In the current study MLVA typing has been performed based on 6 loci on 45 C. burnetiipositive samples to study the genetic background of this bacterium in domestic ruminants in Spain.
MLVA typing revealed a substantial genetic diversity among C. burnetii from domestic ruminants in Northern Spain as shown in the minimum spanning tree, with 11 distinct genotypes being identified. None of the MLVA profiles found here were similar to the profiles identified in the $\mathrm{Q}$ fever outbreak episodes in The Netherlands [13] or Poland [26]. The MLVA genotypes (I, J, M, S and $\mathrm{T})$ described in the current study have been found before, indicating a wide dissemination of the described MLVA genotypes throughout Europe. MLVA genotypes I, J and M have been found in cattle milk from France, Netherlands, Portugal, Spain and Switzerland [14], and have also been incidentally found in 8 human clinical samples (placenta and heart valve) from France, according to an in-house database containing 61 different $C$. burnetii MLVA genotypes from 231 human, caprine, ovine and cattle clinical samples and cows milk obtained from Canada, France, Germany, The Netherlands, Portugal, Qatar, Russia, Saudi Arabia, Slovak Republic, Spain, Switzerland, United Kingdom and USA. Moreover, MLVA genotypes $\mathrm{S}$ and $\mathrm{T}$ have also been incidentally found in 8 human clinical samples (blood and valve) from France and Portugal and in 6 ruminant samples (goat and sheep) from Portugal [27].

In addition, 6 new MLVA profiles were identified ( $\mathrm{Z}$ and $\mathrm{AA}$ in sheep, $\mathrm{AE}$ in goats, and $\mathrm{AB}, \mathrm{AC}$, and $\mathrm{AD}$ in cattle) which so far have not been detected in human or animal samples. However, some of these new genotypes differ in only one marker from other previously defined and may represent microvariants of the founder genotype.

Interestingly, variations in MLVA genotypes were observed throughout consecutive reproductive seasons in some sheep farms. This was the case on Farm Sh2, where genotypes detected in air samples were different from those detected in aborted ewes. This also happened in farms Sh4 and Sh5, where partial genotypes in environmental or animal samples were different. Typing data provided important epidemiological information about the sources of infection, and explained previous observations when C. burnetii appeared in environmental surfaces while no animal shedders were present in the sheep flocks [28].

Since several C. burnetii genotypes can be present on a farm, BTM samples might be contaminated with 


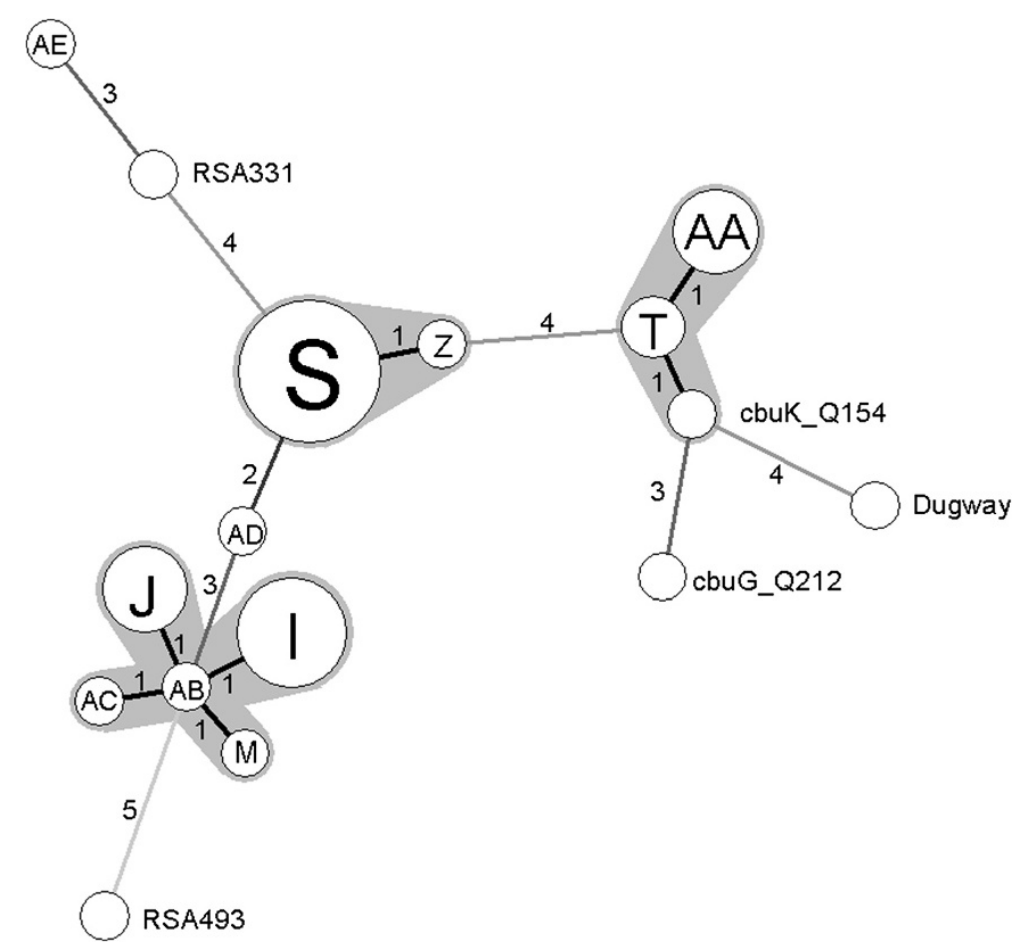

Figure 1 Minimum spanning tree showing the relationship between the obtained MLVA genotypes identified in this study and five sequenced C. burnetii strains, i.e. Dugway (Genbank accession number CP000733), RSA331 (CP000890), Nine Mile RSA493 (AE016828), CbuG Q212 (CP001019) and CbuK Q154 (CP001020) were determined in silico [13] using the published sequences. Each circle represents a unique genotype; the size of the circle corresponds to the number of samples with that genotype. Only full MLVA genotypes were included in this analysis. Branch labels and connecting lines correspond to the number of different markers between the genotypes. Genotypes connected by a gray background differ in only one marker from each other and may represent microvariants of one founder genotype. One cluster represents genotypes (I, J, M, AB and AC) obtained exclusively in cattle. The genotypes from cattle, goats and sheep (S, Z, AA and T) are clustered in two other groups.

Table 3 MLVA and MST genotypes of C. burnetii strains isolated from domestic ruminants in Spain

\begin{tabular}{|c|c|c|c|c|c|c|c|c|c|c|c|c|c|c|}
\hline \multirow[b]{2}{*}{ Farm } & \multirow[b]{2}{*}{ Source } & \multirow[b]{2}{*}{ Origin } & \multirow[b]{2}{*}{ Year } & \multirow[b]{2}{*}{$\mathrm{Ct}$} & \multirow[b]{2}{*}{ MLVA } & \multirow[b]{2}{*}{ MST } & \multicolumn{8}{|l|}{ MST } \\
\hline & & & & & & & $\operatorname{cox} 2$ & cox 5 & CoX18 & $\operatorname{cox} 22$ & COX37 & CoX51 & coX56 & COX61 \\
\hline Gt1 & placenta & Alava & 2010 & 8.9 & S & 13 & 3 & 5 & 1 & 5 & 4 & 5 & 5 & 2 \\
\hline Gt2 & placenta & Bizkaia & 2010 & 5.4 & $\mathrm{AE}$ & 18 & 3 & 8 & 1 & 3 & 4 & 7 & $-{ }^{1}$ & 3 \\
\hline Gt3 & placenta & Toledo & 2010 & 10.1 & $\mathrm{~T}$ & 8 & 5 & 4 & 2 & 1 & 5 & 3 & 3 & 4 \\
\hline Gt4 & placenta & Zamora & 2005 & 11.2 & $S$ & 13 & 3 & 5 & 1 & 5 & 4 & 5 & 5 & 2 \\
\hline DC1 & Individual milk & Girona & 2011 & 23.9 & I & 20 & 3 & 2 & 6 & 5 & 4 & 4 & 10 & 5 \\
\hline DC2 & Individual milk & Bizkaia & 2010 & 24.2 & J & 20 & 3 & 2 & 6 & 5 & 4 & 4 & 10 & 5 \\
\hline DC2 & BTM & Bizkaia & 2010 & 26.9 & J & 20 & 3 & 2 & 6 & 5 & 4 & 4 & 10 & 5 \\
\hline DC5 & Individual milk & Navarra & 2011 & 27.7 & । & $20^{*}$ & 3 & 2 & 6 & 5 & 4 & 4 & - & 5 \\
\hline DC6 & BTM & Cantabria & 2011 & 25.9 & $A C$ & 20 & 3 & 2 & 6 & 5 & 4 & 4 & 10 & 5 \\
\hline DC7 & Individual milk & Lugo & 2011 & 31.7 & $A D$ & 13 & 3 & 5 & 1 & 5 & 4 & 5 & 5 & 2 \\
\hline DC8 & BTM & Bizkaia & 2009 & 25.2 & S & $13^{*}$ & 3 & 5 & 1 & 5 & 4 & 5 & - & 2 \\
\hline Sh1 & placenta & Alava & 2004 & 6.4 & $\mathrm{~T}$ & $8^{*}$ & 5 & 4 & 2 & 1 & 5 & - & 3 & 4 \\
\hline Sh2 & Faeces & Gipuzkoa & 2007 & 16.0 & AA & $8^{*}$ & 5 & 4 & 2 & 1 & 5 & 3 & - & 4 \\
\hline Sh3 & Vaginal swab & Gipuzkoa & 2009 & 27.9 & S & 13 & 3 & 5 & 1 & 5 & 4 & 5 & 5 & 2 \\
\hline Sh4 & Vaginal swab & Gipuzkoa & 2008 & 25.0 & Partial & 13 & 3 & 5 & 1 & 5 & 4 & 5 & 5 & 2 \\
\hline
\end{tabular}

${ }^{1}=$ no result obtained in the corresponding spacer, giving an estimated MST profile marked with an asterisk $(*)$. 
several different genotypes. However, apart from one sample (from farm DC10) that could not be typed, clean chromatograms were obtained by MST in all BTM samples tested in this study, suggesting the presence of only one genotype per BTM sample. This was also supported by the MLVA results.

Looking at MLVA genotyping results on individual milk samples, apart from one sample from farm DC2, only one genotype was detected per individual milk sample and per farm, as shown in farms DC1 and DC3. In the sample from farm DC2 (Bizkaia region), more than one allele per locus was observed, suggesting the presence of at least two or more different MLVA genotypes. In addition, the presence of highly similar C. burnetii genotypes (I, J, M, AB and AC) in cattle milk may indicate a widespread dissemination of a specific cattleadapted strain, as previously reported [14].

MLVA typing has shown to be less laborious and more discriminatory than MST [15]. However, MST has the advantage of using standardized nomenclature, and having databases that allow easy comparison of results between laboratories and studies. It is interesting that the MST genotype involved in the human Q fever outbreak in The Netherlands (MST33), linked to goats and sheep and found also in Germany and France [17], was not detected in the present study. However, the most common genotype (MST13), which was identified in the three ruminant species in Spain, had been identified before in human $Q$ fever cases in France, and recently in Portugal [27]. Other MST genotypes detected in this study, had also been previously reported. MST8, detected here in goats and probably present in sheep (partial profile), has been found before in human samples and in one ovine sample from Spain, France and USA, and in human Q fever chronic cases from Portugal [27]. MST18, found only on 1 goat farm was isolated before from human and animal (sheep and goats) clinical samples in France, Italy, Romania, Greece, Slovak Republic and Germany according to the MST database (http://ifr48.timone.univ-mrs.fr/MST_Coxiella/mst/). Finally, MST20, found here in cattle, had been identified in animal and human clinical samples from France, Germany, Netherlands and USA $[16,17]$. Human isolates need to be genotyped with the same techniques used here on animal samples to identify the most important animal source for human $Q$ fever infection in this Spanish region. The only genotyping study carried out in Spain, used PCR and RLB hybridization to determine the presence/absence of 8 ORFs in order to compare C. burnetii isolates from domestic ruminants $(\mathrm{n}=29)$ and human cases $(\mathrm{n}=24)$. The authors identified some related genomic groups in C. burnetii isolated from humans, sheep and goats, but not from cattle [21]. This is in agreement with the results obtained in The
Netherlands, where prevalence of C. burnetii DNA in dairy cattle is high [29] but MLVA and MST genotypes detected in cattle are different from those involved in the human Q fever outbreak [12-14,17].

\section{Conclusions}

Understanding the distribution of C. burnetii genotypes present in a region is critical to identify the major sources of infection, and implement efficient farm-based control measures to reduce human exposure to the pathogen. However, it is necessary to harmonize genotyping techniques to be used in Coxiella epidemiological studies, so that results can be exchanged and readily comparable among different laboratories and studies. Likewise, a common website where all typing data can be submitted and easily accessed is necessary for timely identification of new strains.

\section{Abbreviations}

MLVA: Multiple locus variable number tandem repeats analysis; MST: Multispacer sequence typing; qPCR: Real-time PCR; IAC: Internal amplification control; Ct: Cycle threshold.

\section{Competing interests}

Authors declare that there are no financial competing interests.

\section{Authors' contributions}

$\mathrm{JA}$ and JT were responsible for laboratorial analyses and assisted with interpretation of data; AP provided samples and made DNA extractions; JT and $\mathrm{AH}$ assisted with discussion of results and writing the manuscript; $\mathrm{ALG}$ coordinated sample selection and wrote the manuscript; MNF and CK supervised laboratory work and critically revised the manuscript. All authors revised the manuscript and approved it in its final version.

\section{Acknowledgments}

This study was supported by Spanish National Institute for Agricultural and Food Research and Technology (INIA RTA 2009-00017-00) and the European Regional Development Fund (ERDF). AP is the recipient of a predoctoral fellowship from INIA.

\section{Author details}

${ }^{1}$ NEIKER-Instituto Vasco de Investigación y Desarrollo Agrario, Department of Animal Health, Derio, Bizkaia, Spain. ${ }^{2}$ Canisius Wilhelmina Hospital,

Department of Medical Microbiology \& Infectious Diseases, Nijmegen, The Netherlands.

Received: 7 September 2012 Accepted: 4 December 2012

Published: 10 December 2012

\section{References}

1. Angelakis E, Raoult D: Q fever. Vet Microbiol 2009, 140:297-309.

2. Woldehiwet $Z$ : $\mathrm{Q}$ fever (coxiellosis): epidemiology and pathogenesis. Res Vet Sci 2004, 77:93-100.

3. Arricau-Bouvery $\mathrm{N}$, Rodolakis A: Is $\mathrm{Q}$ fever an emerging or re-emerging zoonosis? Vet Res 2005, 36:327-349.

4. Rodolakis A, Berri M, Hechard C, Caudron C, Souriau A, Bodier CC, et al: Comparison of Coxiella burnetii shedding in milk of dairy bovine, caprine, and ovine herds. J Dairy Sci 2007, 90:5352-5360.

5. Tissot-Dupont H, Amadei MA, Nezri M, Raoult D: Wind in November, Q fever in December. Emerg Infect Dis 2004, 10:1264-1269.

6. Jager C, Willems H, Thiele D, Baljer G: Molecular characterization of Coxiella burnetii isolates. Epidemiol Infect 1998, 120:157-164.

7. Hendrix LR, Samuel JE, Mallavia LP: Differentiation of Coxiella burnetii isolates by analysis of restriction-endonuclease-digested DNA separated by SDS-PAGE. J Gen Microbio/ 1991, 137:269-276. 
8. Nguyen SV, Hirai K: Differentiation of Coxiella burnetii isolates by sequence determination and PCR-restriction fragment length polymorphism analysis of isocitrate dehydrogenase gene. FEMS Microbio/ Lett 1999, 180:249-254.

9. Sekeyova Z, Roux V, Raoult D: Intraspecies diversity of Coxiella burnetii as revealed by com 1 and mucZ sequence comparison. FEMS Microbiol Lett 1999, 180:61-67.

10. Zhang GQ, To H, Yamaguchi T, Fukushi H, Hirai K: Differentiation of Coxiella burnetii by sequence analysis of the gene (com 1) encoding a $27-\mathrm{kDa}$ outer membrane protein. Microbiol Immunol 1997, 41:871-877.

11. Arricau-Bouvery N, Hauck Y, Bejaoui A, Frangoulidis D, Bodier CC, Souriau A, et al: Molecular characterization of Coxiella burnetii isolates by infrequent restriction site-PCR and MLVA typing. BMC Microbiol 2006, 6:38.

12. Roest HI, Ruuls RC, Tilburg JJ, Nabuurs-Franssen $M H$, Klaassen $C_{\text {, Vellema } P \text {, }}$ et al: Molecular epidemiology of Coxiella burnetii from ruminants in $\mathrm{Q}$ fever outbreak, the Netherlands. Emerg Infect Dis 2011, 17:668-675.

13. Tilburg JJ, Rossen JW, van Hannen EJ, Melchers WJ, Hermans MH, van de BJ, et al: Genotypic diversity of Coxiella burnetii in the 2007-2010 Q fever outbreak episodes in The Netherlands. J Clin Microbiol 2012, 50:1076-1078.

14. Tilburg JJ, Roest HJ, Nabuurs-Franssen MH, Horrevorts AM, Klaassen CH: Genotyping Reveals the Presence of a Predominant Genotype of Coxiella burnetii in Consumer Milk Products. J Clin Microbiol 2012, 50:2156-2158

15. Tilburg JJ, Roest HJ, Buffet S, Ruuls RC, Willemsen PT, Nabuurs-Franssen MH, et al: Evaluation of three different genotyping methods for the molecular characterization of $C$. burnetii. In 6th International Meeting on Rickettsiae and Rickettsial Diseases. Crete (Greece) 5-7th June; 2011:84.

16. Glazunova O, Roux V, Freylikman O, Sekeyova Z, Fournous G, Tyczka J, et al: Coxiella burnetii genotyping. Emerg Infect Dis 2005, 11:1211-1217.

17. Tilburg JJ, Roest HJ, Buffet S, Nabuurs-Franssen MH, Horrevorts AM, Raoult $D$, et al: Epidemic genotype of Coxiella burnetii among goats, sheep, and humans in the Netherlands. Emerg Infect Dis 2012, 18:887-889.

18. Alvarez J, Perez A, Mardones FO, Perez-Sancho M, Garcia-Seco T, Pages E, et al: Epidemiological factors associated with the exposure of cattle to Coxiella burnetii in the Madrid region of Spain. Vet J 2012, 194:102-107.

19. Rodríguez NF, Carranza C, Bolaños M, Pérez-Arellano JL, Gutiérrez C: Seroprevalence of Coxiella burnetii in domestic ruminants in Gran Canaria Island. Spain. Transbound Emerg Dis 2010, 57:66-67.

20. Ruiz-Fons F, Astobiza I, Barandika JF, Hurtado A, Atxaerandio R, Juste RA, et al: Seroepidemiological study of $Q$ fever in domestic ruminants in semi-extensive grazing systems. BMC Vet Res 2010, 6:3.

21. Jado I, Carranza-Rodriguez C, Barandika JF, Toledo A, Garcia-Amil C, Serrano B, et al: Molecular method for the characterization of Coxiella burnetii from clinical and environmental samples: variability of genotypes in Spain. BMC Microbiol 2012, 12:91.

22. Astobiza I, Barandika JF, Ruiz-Fons F, Hurtado A, Povedano I, Juste RA, et al Coxiella burnetii shedding and environmental contamination at lambing in two highly naturally-infected dairy sheep flocks after vaccination. Res Vet Sci 2010, 91:e58-e63.

23. Astobiza I, Barandika JF, Hurtado A, Juste RA, García-Pérez AL: Kinetics of Coxiella burnetii excretion in a commercial dairy sheep flock after treatment with oxytetracycline. Vet J 2010, 184:172-175.

24. Willems H, Thiele D, Frolich-Ritter R, Krauss H: Detection of Coxiella burnetii in cow's milk using the polymerase chain reaction (PCR). Zentralb/ Veterinarmed B 1994, 41:580-587.

25. Klaassen $\mathrm{CH}$, Nabuurs-Franssen MH, Tilburg JJ, Hamans MA, Horrevorts AM: Multigenotype Q fever outbreak, the Netherlands. Emerg Infect Dis 2009, 15:613-614

26. Chmielewski T, Sidi-Boumedine K, Duquesne V, Podsiadly E, Thiery R, Tylewska-Wierzbanowska S: Molecular epidemiology of $\mathrm{Q}$ fever in Poland. Pol J Microbiol 2009, 58:9-13.

27. Santos AS, Tilburg JJ, Botelho A, Barahona MJ, Nuncio MS, Nabuurs-Franssen $\mathrm{MH}$, et al: Genotypic diversity of clinical Coxiella burnetii isolates from Portugal based on MST and MLVA typing. Int J Med Microbiol 2012, 302:253-256.

28. Astobiza I, Barandika JF, Ruiz-Fons F, Hurtado A, Povedano I, Juste RA, et al: Four-Year Evaluation of the Effect of Vaccination against Coxiella burnetii on Reduction of Animal Infection and Environmental Contamination in a Naturally Infected Dairy Sheep Flock. Appl Environ Microbiol 2011, 77:7405-7407.

29. Muskens J, van Engelen E, van Maanen C, Bartels C, Lam TJ: Prevalence of Coxiella burnetii infection in Dutch dairy herds based on testing bulk tank milk and individual samples by PCR and ELISA. Vet Rec 2011, 168:79.

doi:10.1186/1746-6148-8-241

Cite this article as: Astobiza et al: Genotyping of Coxiella burnetii from domestic ruminants in northern Spain. BMC Veterinary Research 2012 8:241.

\section{Submit your next manuscript to BioMed Central and take full advantage of:}

- Convenient online submission

- Thorough peer review

- No space constraints or color figure charges

- Immediate publication on acceptance

- Inclusion in PubMed, CAS, Scopus and Google Scholar

- Research which is freely available for redistribution

Submit your manuscript at www.biomedcentral.com/submit
C) Biomed Central 